Dr MILUTIN ŽIVKOVIĆ, naučni saradnik

Institut za srpsku kulturu

Priština - Leposavić, Republika Srbija

mzivkovickv@gmail.com

originalan naučni rad

UDK: 355.426(497.11+497.16)"1941/1942"

primljeno: 23. maj 2018.

323.281(497.11)"1941/1942"

94(497.11)"1941/1942"

prihvaćeno: 10. oktobar 2018.

https://doi.org/10.29362/ist20veka.2019.1.ziv.75-92

\title{
REVOLUCIONARNI TEROR U NOVOVAROŠKOM, PRIJEPOLJSKOM I PLJEVALJSKOM SREZU OKTOBAR 1941-MAJ 1942*
}

APSTRAKT: Članak razmatra uzroke i stepen revolucionarnog nasilja koji su jugoslovenski komunisti vršili krajem 1941. i tokom prve polovine 1942. godine u Starom Rasu, kao i njegove posledice po lokalno stanovništvo i samu Partiju. Posebna pažnja je posvećena utvrđivanju vremenskog okvira unutar kojeg je vršena tortura, oblicima koje je poprimila, broju žrtava koje je odnela $i$ terminologiji kojom se ima označiti.

KLJUČNE REČI: teror, Josip Broz Tito, Milovan Đilas, Nova Varoš, Pljevlja, Prijepolje, partizani, četnici

Posle teškog poraza koji su partizani pretrpeli od nemačkih snaga kod Užica krajem novembra 1941. godine, deo jedinica predvođen Josipom Brozom evakuisao se preko Uvca u italijansku okupacionu zonu. Predah od okupatorskih hajki koji je tako obezbeđen, rukovodstvo Komunističke partije Jugoslavije (KPJ) iskoristilo je za reorganizaciju snaga, ali i kritičko sagledavanje neuspeha u zapadnoj Srbiji. Krivica je, međutim, obuhvatila širok krug boraca i stanovništva, a ceo proces ubrzo dobija ekstreman karakter, kroz „radikalizaciju klasne borbe“. Ona je trajala nekoliko meseci i prožela je sve slojeve društva. Njenu oštricu osetili su i sami partizani, pa i članovi KPJ. Međutim, zbog usmerenosti komunista na izvođenje društvene revolucije i preuzimanje vlasti još tokom rata, prve egzekucije neistomišljenika u pojedinim delovima Jugoslavije, uključujući Stari Ras, počinju i ranije, tokom leta i jeseni 1941. godine. Ulaskom u fazu „levih skretanja“ komunističko nasilje samo poprima masovan oblik. Likvidacije „klasnih neprijatelja“, pri tom, odišu surovošću, pa se ekstremizam nameće kao osnovna odlika celog procesa.

$\mathrm{Za}$ termin početka revolucionarnog terora uzima se sastanak Politbiroa Centralnog komiteta (CK) KPJ u selu Drenovi kod Prijepolja 7. decembra 1941.

\footnotetext{
* Rad je deo projekta Materijalna i duhovna kultura Kosova i Metohije (178028), koji finansira Ministarstvo prosvete, nauke i tehnološkog razvoja Republike Srbije.
} 
godine. Josip Broz je tada, pošto mu ostavka nije prihvaćena, između ostalog, odlučio da se započne rigorozna borba protiv ideološkog neprijatelja, spolja i iznutra, ali i svih onih čiji stav nije išao na ruku komunistima. Isti, ako ne i oštriji stav, zauzeo je Edvard Kardelj. Podršku novom kursu partijske politike dao je i Milovan Đilas. ${ }^{1}$

Vrhovni štab narodnooslobodilačkih partizanskih odreda Jugoslavije (VŠJ) je, stoga, 19. decembra naredio potčinjenim komandama da ,nesposobne kadrove (treba - M. Ž.) uklanjati“،, a u slučaju neizvršenja naređenja iste odmah „streljati““2 ${ }^{2}$ Slične instrukcije za odnos prema boračkom kadru i klasnom neprijatelju dobile su i jedinice koje su vraćene na prostor zapadne Srbije, ali i one u Bosni, Sremu i Sloveniji. ${ }^{3}$ U međuvremenu, Josip Broz je sa najbližim saradnicima zamalo izbegao zarobljavanje 14. decembra kada su Italijani slučajno naišli na njegov štab u Drenovi. ${ }^{4}$ Povećan osećaj nesigurnosti, na koji je partizanski komandant bio posebno osetljiv tokom celog rata, dodatno je uticao na zaoštravanje odnosa prema onima koji su smatrani za neprijatelje. ${ }^{5}$

Delegat VŠJ za Crnu Goru Ivan Milutinović je stoga, prolazeći kroz Stari Ras, postavio pitanje likvidacije lokalnih ,„spijuna i petokolonaša“. On je u razgovoru sa predstavnicima Glavnog štaba narodnooslobodilačkih partizanskih odreda za Sandžak (GŠS) odredio koji se ljudi i na koji način imaju pogubiti. Josip Broz je, zatim, naredio komandi Crnogorsko-sandžačkog odreda da na teritoriji pod njenom kontrolom (delovi Pljevaljskog i Bijelopoljskog sreza), povede otvorenu borbu protiv četnika, te da ,,po svaku cijenu“ izvrši njihovu likvidaciju. ${ }^{6}$

Generalni sekretar KPJ će ubuduće biti jasniji prema borbi protiv ideološkog neprijatelja. U naređenju datiranom na 14. februar 1942. i upućenom na istu adresu, on kaže sledeće: „Morate obavezno streljati sve one koji su potpomagali četnike i bili naklonjeni njima; Isto tako raščistiti s labavim i kolebljivim elementima; Pri svemu tome morate biti potpuno energični i bez svakog milosrđa. Ti nitkovi nište naše najbolje kadrove. Rade u zajednici s okupatorom, te vodimo tešku, neravnu borbu. Ako u ovom pogledu učinite ma kakav propust činićemo štab odgovornim“" 7

\footnotetext{
1 Branko Petranović, Srbija u Drugom svetskom ratu 1939-1945 (Beograd: Vojno-izdavački centar, 1992), 298; Venceslav Glišić, Susreti i razgovori. Prilozi za biografiju Petra Stambolića (Beograd: Službeni glasnik, 2010), 16; Vladimir Dedijer, Veliki buntovnik Milovan Đilas (Beograd: Prosveta, 1991), 254-255, 262; Milovan Djilas, Wartime (New York: Harcourt Brace Jovanovich, 1977), 118-119, 123.

${ }^{2}$ Vojni arhiv (VA), Narodnooslobodilačka vojska (NOVJ), kutija (kut.) 171, fascikla (fasc.) 6, dokument (dok.) 8, 5.

${ }^{3}$ Бранко Петрановић, „О левим скретањима КПЈ крајем 1941. и у првој половини 1942“, Зборник за историју Матиие српске, бр. 4, (1971), 53-55, 58.

${ }^{4}$ Broz je posle rata svedočio da je situacija bila ,gusta“ i da su mu Italijani „došli pod nos“. AJ, fond 837, Kabinet Predsednika Republike (KPR), II-1/1216, 1; Archivio dell'Ufficio storico dello Statomaggiore dell'Esercito (AUSSME), Divisione „Pusteria“, bus. N-4/657, Bollettino informazioni nr. 134, 14. 12. 1941, 1; Ibid., nr. 135, 15. 12. 1941, 1; Vladimir Dedijer, Dnevnik: 1941-1944, I (Beograd-Sarajevo: Prosveta-Svjetlost, 1970), 73.

${ }^{5}$ Milovan Đilas, Druženje s Titom (Beograd: Goran, 1990), 31, 99.

${ }^{6} \mathrm{VA}$, NOVJ, kut. 171, fasc. 1, dok. 13, 1; Isto, kut. 2A, fasc. 1, dok. $2,1$.

${ }^{7}$ Isto, kut. 2, fasc. 2, dok. 16, 1; V. Dedijer, Veliki buntovnik, 255.
} 
Nekoliko dana ranije i Milovan Đilas je pisao o razvoju revolucionarne borbe na sličan način: „U tu (drugu - M. Ž.) fazu treba i mi da uđemo svjesno, bez kolebanja u tim pokrajinama. Daleko od toga, da to znači da ne treba voditi borbu protiv okupatora, ali često je ta borba skoro nemogućna dok se ne raščiste računi s unutarnjim (buržoaskim) neprijateljem“. ${ }^{8}$ Njegov partijski kolega Edvard Kardelj je poručivao da se pred komuniste postavlja pitanje „ko će koga“, te da bi trebalo „,izbaciti klasno obojene narodnooslobodilačke parole“. Polemišući sa njim, Ivo Lola Ribar je smatrao da je „teror odlična stvar“ ako to narod „razume i opravdava“. ${ }^{9}$ GŠ za Crnu Goru i Boku tražio je dalje, od potčinjenih jedinica tokom februara 1942. godine, ,likvidaciju bandi“ u Andrijevačkom i Beranskom srezu, ${ }^{10}$ dok je Moše Pijade zapovedao da se svaki četnik iz Vasojevića likvidira. ${ }^{11}$

Komunisti zvanično prestaju sa radikalnim pristupom klasnoj borbi tokom aprila 1942. godine. Posle kritike Kominterne da KPJ ide suviše „u levo“, koja je u martu stigla iz Moskve, Josip Broz je 4. aprila odlučio da se revolucionarno nasilje obustavi, te da se ubuduće ubistva „petokolonaša“ vrše „oprezno“ i ,politički pripremljeno“. ${ }^{12} \mathrm{Na}$ tragu ovih zahteva, Đilas je obavestio niže partijske instance da se mora obratiti velika pažnja kada su u pitanju likvidacije ljudi i konfiskacija imovine, koje su od tada imale da pogađaju samo ,izrazite petokolonaše “. ${ }^{13}$ Teror će se, međutim, na nekim mestima nastaviti. ${ }^{14}$

Istoričar Branko Petranović kao razloge zbog kojih je KPJ sprovodila revolucionarni teror navodi: teške poraze partizanskih snaga oko Užica i Pljevalja, jačanje četničkih snaga i njihovo približavanje okupatoru, kao i neuspeh nemačke ofanzive pred Moskvom, posle koje se pogrešno očekivao slom Trećeg rajha. ${ }^{15}$ Dodali bismo još dva. Prvi je da su jugoslovenski komunisti po ugledu na revolucionare u Rusiji, na čija su se iskustva često oslanjali, nasilje nad neistomišljenicima smatrali legitimnim sredstvom preuzimanja vlasti. O drugom svedoči Milovan Đilas kada kaže da je Josip Broz bio „naglog i nervoznog temperamenta“ $i$ nekada ,prehitrog reagovanja“. ${ }^{16}$

\footnotetext{
${ }^{8}$ VA, NOVJ, kut. 3, fasc. 3, dok. 1, 4.

${ }^{9}$ Б. Петрановић, „О левим скретањима КПЈ“, 56, 62-63.

${ }^{10}$ Коста Николић, Историја Равногорског покрета 1941-1945, књига 1 (Београд: Завод за уџбенике, 2014), 455.

${ }^{11}$ VA, NOVJ, kut. 173, fasc. 2, dok. 23, 1. Krajem 1941. i početkom 1942. godine komunisti su u ova dva sreza ubili najmanje 21 osobu, među kojima: predsednika opštine Budimske Tomicu Čukića, učitelja Đorđija Bogavca, sreskog načelnika Nikolu Lašića, predsednika opštine Šekular Batrića Božovića, kapetana Vasa Labana i druge. VA, Četnička arhiva (Ča), kut. 132, fasc. 1, dok. 19, 1-6; VA, NOVJ, kut. 175, fasc. 4, dok. 27, 4.

12 Б. Петрановић, „О левим скретањима КПЈ“, 46, 57, 62.

${ }^{13}$ VA, NOVJ, kut. 173, fasc. 2, dok. 27, 1.

${ }^{14} \mathrm{O}$ tome svedoči pismo generala Mihailovića jugoslovenskoj vladi u Londonu od 24. aprila 1942, u kojem traži od nadležnih da se obrate vladi SSSR-a kako bi ona uticala na KPJ da više ne ubija živalj u Crnoj Gori i Starom Rasu. VA, Ča, kut. 275, fasc. 2, dok. 3, 1.

${ }^{15}$ B. Petranović, Srbija u Drugom svetskom ratu, 41-43.

${ }^{16}$ M. Đilas, Druženje, 31, 42, 123; К. Николић, Тито говори што народ мисли. Култ Јосипа Броза Тита 1944-1949 (Београд: Институт за савремену историју, Службени лист Србије и Црне Горе, 2006), 45.
} 
Koji razlog je među navedenima ključan možda najbolje govori podatak da su komunističke likvidacije u Starom Rasu počele još u oktobru 1941. godine. Pripadnici Mileševske partizanske čete su, na primer, 27. oktobra upali u manastir Mileševu i zarobili tamošnjeg igumana Nestora Trkulju. Potom su ga streljali bez jasno utvrđene krivice. ${ }^{17}$ C̆etiri dana kasnije partizani su likvidirali Draga Lelekovića i Zdravka Kurčubića u Ljepojevićima, a zbog povezanosti sa četnicima. Iz istih razloga, 19. novembra u Kokinom Brodu zarobljen je ugledni učitelj Diko Purić. On je odveden u pravcu Užica i ubijen. ${ }^{18}$

Zatim su Zlatarska i Sjenička partizanska četa u selu Akmačići, 21. novembra, zarobile zlatarskog vojvodu Vlajka Ćurčića i njegove saradnike inženjera Ljubomira Ranitovića, bivšeg člana Zemljoradničke stranke i četničkog komandanta za Sjenički srez, žandarmerijskog narednika Milosava Ranitovića, studenta prava Vasilija Purića, bogoslova Simu Despotovića i još neke. Oko 15 ljudi je, zatim, odvedeno u selo Radoinju. Tamo su komunisti streljali: 62-godišnjeg Ćurčića (komitu iz vremena osmanske okupacije), oba Ranitovića, Vasilija Purića i bogoslova Vrbickog. Njihovi leševi su bačeni u jednu baru pored Uvca. ${ }^{19}$

Slična situacija je bila i u Pljevaljskom srezu. Prilikom mobilizacije ljudstva 2. novembra u Kotlajićima likvidirana su dvojica Srba koja su odbila da se pridruže partizanima. Nešto kasnije, 21. novembra, jedna partizanska grupa došla je u Meljačku opštinu u sklopu priprema za oslobođenje Pljevalja. U selu Podgoru ubili su lokalnog učitelja jer nije želeo da ide u borbu. Narednog dana komunisti su u samom Meljaku likvidirali dvojicu sinova lokalnog sveštenika i opštinskog pisara. Svi su ubijeni jer nisu želeli pod komunistički barjak. Istovremeno je opljačkana stoka stanovnicima sela Krnjača i Adrovići. ${ }^{20}$

Potom je usledilo ubistvo jednog od najuglednijih ljudi u Starom Rasu, arhimandrita Serafima Džarića, dugogodišnjeg starešine manastira Sv. Trojica i tada još uvek aktuelnog člana Upravnog odbora Dabrobosanske mitropolije. On je likvidiran tokom bitke za Pljevlja 1. decembra 1941. i to u zgradi gimnazije koju su partizani zauzeli. Zajedno sa 66-godišnjim duhovnikom ubijen je i direktor škole Dobrosav Miletić. Njihovo umorstvo bilo je direktna posledica naređenja partizanske komande da se posle oslobođenja grada počne sa ,žestokom borbom protiv špijuna i 5. kolone“. ${ }^{21}$

\footnotetext{
${ }^{17}$ AUSSME, Divisione „Pusteria“, bus. N-4/656, Bollettino informazioni nr. 69, 1. 10. 1941, 1; Хилмија Хасанагић, У суровој школи (Београд: Просвета, 1962), 76-77.

18 Златарске новости, 14. 9. 2001; Исто, 27. 4. 2001; Исто, 28. 6. 2002.

${ }^{19}$ AUSSME, Divisione „Pusteria“, bus. N-4/656, Bollettino informazioni nr. 123, 24. 11. 1941, 1; Istorijski arhiv Kraljevo (IAK), fond 420, NOB, kut. 14, Referat S. Čekanovića, Hronika Sjenice, 228-229; Istorijski arhiv Užice (IAU), Memoarska građa (MG), d(osije) 1271, 3; Мирко Ћуковић, Путовање у слободу: ратне белешке (Нова Варош: СИЗ културе Општине, 1979), 106; Станко Равић, Међу орловима Златара (Пријепоље: Полимље, 1972), 129-130; Владимир Ј. Шапоњић, Крв увачких пећина и друге ноћне море (Београд: Драслав партнер, 2013), 7-8.

20 AUSSME, Divisione,„Pusteria“, bus. N-4/656, Bollettino informazioni nr. 109, 10. 11. 1941, 1; Ibid., nr. 121, 22. 11. 1941, 1; Ibid., nr. 122, 23. 11. 1941, 1-2.

${ }^{21}$ Ibid., bus. N-4/657, Relazione sul combattimento del giorno 1. 12. 1941, Nr. 2800, 9. 12. 1941, 3-4; Ibid., Preparazione e condotta dell'attacco da parte dei ribelli, Allegato n. 2 al foglio n.
} 
Prelaskom većih komunističkih snaga preko Uvca početkom decembra povećao se pritisak na lokalno stanovništvo, ali i borce u partizanskim redovima. $\mathrm{Na}$ oslobođenoj teritoriji, koju su partizani formirali sa centrom u Novoj Varoši, ključnu ulogu u ovom procesu imao je Milovan Đilas, iako on to negira u svojim sećanjima. ${ }^{22}$ Prvo se pristupilo ,čistki i organizaciji“ ,umornog, gladnog, pocepanog, bosog i vašljivog“ ljudstva unutar jedinica koje su se povukle iz Užica. Nju su, pored Đilasa, vodili Ivo Lola Ribar i Aleksandar Ranković. Iz borbenih redova uklanjano je „,sve ono što je unosilo nesigurnost ili demoralizaciju““ ${ }^{23}$

Tako je u Ariljskoj četi došlo do streljanja dela ljudstva u Kokinom Brodu i Novoj Varoši. Posle ,pročišćivanja“ jedinica je vraćena u matični srez, sa zadatkom da hvata četničke pristalice $\mathrm{i}$,da ih likvidira“ ${ }^{24}$ Početkom decembra pogubljen je i Marko Zvjerota, partizan sa odbrane Užica, bivši „solunac“, na mestu Suvodolu (stratište) u Novoj Varoši. On je osuđen na smrt zbog ubistva jednog muslimana 4. decembra, koga je sam optužio da je ,italijanski špijun" da bi mu oduzeo stoku. Jedan njegov saborac je istovremeno lišen života jer je ukrao nekoliko zlatnika iz jedne kuće u gradu. ${ }^{25}$ Prema svedočanstvu Stevice Kosanovića-Jabučara, člana KPJ koji se tada nalazio u komandi Beogradskog bataljona, Milovan Đilas je, takođe, po dolasku u Novu Varoš presudio da se strelja i nekoliko „Šumadinaca“. Među njima se izdvaja likvidacija pravnika Mileta Cvetića, člana KPJ, a bez jasno utvrđene krivice. ${ }^{26}$

Paralelno sa čistkama u boračkom sastavu, vršeno je obračunavanje sa političkim neistomišljenicima i civilima koji su odbijali da se povinuju komunističkoj vlasti. Đilas je obavestio VŠJ da je 24. decembra sprovedena akcija čišćenja sela Seništa i Kokinog Broda. Tom prilikom su streljana dvojica žandarma, a nekoliko seljaka iz oba sela uzeto za taoce i odvedeno u grad. Zatim su partizani upali u Rutoše i Čelice, razoružali četničke straže i zapretili meštanima da će im spaliti domove ukoliko se ponovo približe njihovim protivnicima. Pokupljeni su, ipak, taoci, među kojima su ubrzo na Suvodolu streljani: Žarko i Dragić Marjanović, Sveta Topalović i Radenko Gordić (svi iz Rutoša). ${ }^{27}$

Nova godina je počela kao što se prethodna završila. Iza partijskih konferencija, kulturno-umetničkih večeri i veselja koja su trajala do duboko u noć, nastavilo se, u okvirima onoga što se može nazvati ,skrivenom“ istorijom, komunističko nasilje. Partizanska straža koja je čuvala most na Mileševci je, na primer, 5. januara streljala jednog pripadnika sjeničke milicije. Istovremeno je Kasim Srna iz Kaćeva, koji je vodio stoku za Prijepolje da bi je prodao italijanskoj posadi,

2800, 1, 3, 6-7; VA, NOVJ, kut. 171, fasc. 5i, dok. 12, 1; Isto, kut. 172a, fasc. 1, dok. 6, 2; Muлешеваи, 7. 1. 2005.

${ }^{22}$ V. Dedijer, Veliki buntovnik, 263. Posle rata Đilas je za vinovnike revolucionarnog terora označio Josipa Broza i njegovo uže okruženje. M. Đilas, Druženje, 33.

${ }^{23}$ AJ, fond 507, CK KPJ, 1941, fasc. 196, 1; M. Djilas, Wartime, 119; V. Dedijer, Dnevnik, 73.

${ }^{24}$ AJ, fond 510, Memoarska građa (MG), d(osije) 1710, 25-27.

${ }^{25}$ IAU, MG, d. 1471, 21-22; Х. Хасанагић, н. д., 88-89; Златарске новости, 10. 12. 2001.

${ }^{26}$ Prema izjavi Steva Kosanovića-Jabučara iz Detroita datoj autoru 29. marta 2013; V. Dedijer, Veliki buntovnik, 176-178, 264-265, 268.

${ }^{27}$ VA, NOVJ, kut. 171, fasc. 6, dok. 9, 1; Златарске новости, 13. 7. 2001. 
uhapšen, a stoka mu je zaplenjena. Iz zatočeništva je pušten tek u februaru na Kamenoj Gori, iako je bio predviđen za streljanje. ${ }^{28}$ Takve sreće, međutim, nisu bili agronom Milan Grbić iz Rutoša i Pero Jeremić iz Bajine Bašte, koji su pogubljeni na lokalitetu Popova livada kod Nove Varoši, verovatno zbog veza sa četnicima. ${ }^{29}$

Lokalno stanovništvo je na komunističku torturu ubrzo počelo da uzvraća istom merom. Prilikom pokušaja jedne partizanske patrole da razoruža Vojina Cmiljanića iz Brda, ovaj je pružio otpor. Usled puškaranja Cmiljanić je ubijen na stratištu Šopot kod Nove Varoši (19. januara). ${ }^{30}$ Kada su, dalje, partizani došli u Aljinoviće da rekviriraju stoku, seljaci su se usprotivili, razoružali ih i proterali nazad u grad. Milovan Đilas je zatim sa par stotina boraca opkolio selo i zarobio nekoliko lica koja su napala njegove ljude. Među njima su streljani: Milan Cuparić, Jevđem Ravić i Jaćin Dragutinović. U selu je opljačkano 80 goveda i 380 ovaca. ${ }^{31}$ Međutim, kada su partizani produžili u obližnje selo Akmačiće da pokupe hranu, ali i nove regrute, zateklo ih je gotovo prazno naselje. Većina meštana je sa stokom pobegla u obližnje četničko selo Lopiže. Tamo se zadržala sve do odlaska snaga KPJ iz Nove Varoši. ${ }^{32}$

U međuvremenu su u partizanskoj komandi u gradu svakodnevno sprovođena saslušanja i suđenja osoba sumnjivih komunistima. O tome je svedočanstvo posle rata ostavilo nekoliko članova KPJ. Đilas je pisao da je u Novoj Varoši bilo puno egzekucija nad ,neprijateljima“ i ,špijunima“ obe veroispovesti. $^{33}$ Jasniju sliku daje sećanje Spasenije Babović, koja je prisustvovala većini isledničkih procesa. Ona je svedočila da ih je vodio upravo Đilas u školi, gde mu je bila kancelarija, i opisala ih rečima: „Najviše se bavio istragom... Znao je da uzme grupu ljudi, da ode u Raniloviće i da pobije čitavu porodicu... Ubije nekoliko ljudi i dođe, takve stvari je radio... Đilas je svašta radio, to je bilo nemoguće“" 34 Sveto Milutinović, tada na mestu stražara u partizanskoj komandi u Novoj Varoši, donosi slična tmurna sećanja. On, između ostalog, kaže: „Obično su dovodili četnike, zarobljene oko Kokinog Broda, tamo prema Negbini. Dovodili su i žandarme neke... Do kasno u noć su ih saslušavali, do 12 sati noću. Nisu ih tukli, već su ih ubijali. Samo su dvojica ostali koji nisu ubijeni“ 35

${ }^{28}$ AUSSME, Divisione „Pusteria“, bus. N-4/657, Bollettino informazioni nr. 157, 6. 1. 1942, 1; IAU, MG, d. 1282, 5-6; M. Djilas, Wartime, 136-137.

29 Златарске новости, 13. 7. 2001.

${ }^{30}$ Исто, 9. 11. 2001.

${ }^{31}$ AUSSME, Divisione,,Pusteria“, bus. N-4/657, Bollettino informazioni nr. 168, 17. 1. 1942, 1; IAK, fond 420, NOB, kut. 14, Referat S. Čekanovića, Hronika Sjenice, 233b; M. Djilas, Wartime, 129-130.

32 Златарске новости, 11. 4. 2002; Исто, 29. 4. 2002; Исто, 31. 5. 2002.

${ }^{33}$ M. Djilas, Wartime, 124.

${ }^{34}$ V. Dedijer, Veliki buntovnik, 264-265. Đilas je kasnije, pod eufemizmom da nije uspeo da sprovede „pravilnu linju CK“, pozvan na odgovornost. Na kraju, ipak, niko nije odgovarao za revolucionarni teror u Crnoj Gori i Starom Rasu. Б. Петрановић, „О левим скретањима КПЈ“, 69-70.

${ }^{35}$ Milutinović je dodao da je Đilas „,upropastio mnoge ljude“. IAU, MG, d. 1471, 14-15. Stevica Kosanović je o njemu svedočio u istom kontekstu, uz žargonsku opasku da je bio „lak na obaraču“. Prema izjavi Steva Kosanovića-Jabučara iz Detroita, datoj autoru 29. marta 2013. 
Pored četnika i žandarma, u arhivskoj građi smo pronašli i imena nekoliko ubijenih civila, kao i kratke primedbe zbog čega su zaslužili takvu kaznu. Među njima se nalaze: trgovac Mustafa Bilalagić i Emin Alispahić kao „organizatori ustaša“, ${ }^{36}$ Hajro Bajrović zbog „stupanja u ustaše“, činovnik Milanko Borisavljević i Jela Ruljević kao „italijanski špijuni““ ${ }^{37}$ Ovom spisku treba dodati i: Đorđa Despića iz Orašca, koji je 25. decembra streljan nedaleko od svoje kuće, Đorđa Anočića iz Nove Varoši (nosilac Karađorđeve zvezde), ubijenog krajem 1941. godine u Negbini, Milana Jadžića iz Kućana, koga je partizanska patrola streljala 15. januara, bivšeg graničara Rada Pušičića iz Drmanovića (ubijen 18. januara u Novoj Varoši), „solunca“ Jevrema Popovića iz Bele Reke, itd. ${ }^{38}$

Neposredno pred partizansko povlačenje iz Nove Varoši početkom februara 1942. godine, dogodilo se poslednje masovno ubistvo. U Kokinom Brodu su se, naime, okupile komunističke snage koje nisu uspele da se domognu okoline Užica. Sa sobom su iz tih krajeva doveli deset zarobljenih seljaka. Posle ispitivanja od strane Milovana Đilasa, svi su u toku noći streljani zbog navodne veze sa četnicima. ${ }^{39}$

Partizanske likvidacije su znale biti veoma surove. Pomenutom Milanu Grbiću egzekutori su u ključaloj vodi držali „noge do kolena i ruke do laktova“ i palili bradu. Ista tortura je vršena nad Ljubisavom i Budimirom Selakovićem i Vulom Buljugićem iz Seništa (streljani 25. decembra na Suvodolu). ${ }^{40} \mathrm{Na}$ lešu Emina Alispahića, koji je nastradao istog dana, bili su prepoznatljivi tragovi mučenja izbijeni zubi i počupani brkovi. Učitelj Bogdan Vitorović i četnici Ilija i Borivoje Vitorović su likvidirani tek posle mučenja, 31 . decembra. ${ }^{41}$ Ovakvi drastični slučajevi poljuljali su veru nekih predratnih komunista u ispravnost ciljeva KPJ, ${ }^{42}$ pogotovo jer su bili propraćeni identičnim oblicima nasilja na drugim mestima, posebno u Kolašinskom srezu. ${ }^{43}$ Ovde je revolucionarni teror dostigao neslućene razmere.

${ }^{36}$ Bilalagić je kao predstavnik Novovaroškog sreza potpisao peticiju koja je 21. aprila 1941. iz Sarajeva poslata na adresu potpredsednika vlade NDH. Ona je nosila molbu da se ,teritorija Sandžaka pripoji Bosni i Hercegovini“. Alispahić je, s druge strane, prilikom oslobođenja Nove Varoši 3. septembra 1941. godine, pod okriljem noći, izveo hrvatsku posadu iz grada. Милутин Живковић, Независна Држава Хрватска у Србији 1941. Усташки режсим у Прибоју, Пријепољу, Новој Вароши и Сјеници (април - септембар 1941) (Београд: Друштво историчара Србије, 2018), 68-69, 215.

${ }^{37}$ Ova 19-godišnja devojka je od strane partizanske trojke odvedena od kuće u ,gluvo“ doba noći tokom januara 1942. i bez jasnog pravnog okvira likvidirana na Suvodolu. Arhiv Srbije (AS), Bezbednosno-informativna agencija (BIA), zbirka 270, Istorijat Nove Varoši, 152-161; IAU, MG, d. 1281, 5-6; Златарске новости, 8. 2. 2002.

38 Златарске новости, 31. 5. 2001; Исто, 29. 6. 2001; Исто, 10. 12. 2001; Исто, 24. 1. 2002; Исто, 31. 7. 2003.

${ }^{39}$ M. Djilas, Wartime, 130-131.

40 Златарске новости, 13. 7. 2001; Исто, 31. 8. 2001; В. Шапоњић, н. д., 26.

41 Златарске новости, 29. 6. 2001; Исто, 8. 2. 2002.

${ }^{42}$ Prema izjavi Steva Kosanovića-Jabučara iz Detroita, datoj autoru 29. marta 2013.

${ }^{43}$ Komunista Bajo Sekulić pisao je Brozu da je ljudstvo pod njegovom komandom vršilo ubistva u tolikom broju da su „napunili jednu poljanu u dolini Tare“ leševima, koju je narod prozvao „Pasje groblje“. Početkom januara 1942. na ovoj lokaciji je ubijeno više od 200 lica koja su viđena kao protivnici KPJ. Prilikom ekshumacije pronađeno je puno izmrcvarenih i unakaženih leševa. VA, NOVJ, kut. 174, fasc. 1 , dok. 37, 1; K. Nikolić, $n$. d., 462. Lokalna štampa je zabeležila da su u Kolašinu po- 
Ubijanje ljudi u Novoj Varoši vršeno je uglavnom u tajnosti. Svedočanstvo o ovim likvidacijama ostavila su dvojica italijanskih vojnika iz bataljona „Bolcano“ (Bolzano) - 11. puk divizije „Pusterija“ (Pusteria), koji su početkom decembra zarobljeni od komunista. Oni su bili određeni za pokopavanje leševa na stratištima. Prema izjavi datoj 13. februara 1942. u Pljevljima, tokom dvomesečnog zarobljeništva prisustvovali su egzekuciji čak ,,85 osuđenika na smrt“. Vojnici-grobari su naveli da je među ubijenim bilo najviše pravoslavaca iz unutrašnjosti sreza, koji su hapšeni kao ,četnici“،, ali i lokalnih muslimana koji su bili označeni kao protivnici KPJ. Ubijanje je vršila posebna grupa od 6-7 partizana koja se bavila samo hvatanjem i likvidiranjem ljudi. Sužnji su na stratište dovođeni ,,potpuno goli, gde su oni koji su pokazivali čvrstinu streljani“،, a oni koji su pravili buku ili pokušavali da pobegnu, ,klati nožem“. Iz konspirativnih razloga žrtve su na stratište izvođene noću (oko 1:00). ${ }^{44} \mathrm{O}$ postojanju masovnih grobnica svedočio je i kapetan Lazar Janić posle dolaska u Novu Varoš 6. februara. Jedno od njegovih prvih naređenja bilo je da se „otkopaju leševi svih žrtava pobijenih od komunista, koje su ovi zatrpavali gde su stigli u gradu i van njega“, i sahrane na gradskom groblju. ${ }^{45}$

Brojka od 85 ubijenih ne predstavlja konačan broj komunističkih žrtava u novovaroškom kraju. Posle reokupacije grada od strane Italijana sredinom 1942. godine, komanda okupatorskog garnizona izvršila je novu procenu broja stradalih. Prema njoj, komunisti su samo među srpskim življem likvidirali pet meštana Nove Varoši i oko stotinu lica iz unutrašnjosti sreza. Broj likvidiranih muslimana se $u$ istom izveštaju ne navodi. ${ }^{46}$

Paralelno sa ubistvima, vršena je masovna pljačka hrane i stoke. Primera radi, partizani su upadali u pročetničko selo Rutoše kada god bi im ponestalo namirnica i uzimali stoku, žito i druge stvari. ${ }^{47}$ Porodici Toljić iz Komarana je oduzeto ,96 tovara heljde i 5,5 vagona ostalog žita“, domaćinstvu Zorića iz Debelje ,25 koza, 12 ovaca“ i nekoliko desetina svinja, Otaševićima iz Brezne 100 ovaca, Despićima iz Orašca „dva para volova, dva konja... pšenica, mrs, vosak“, novovaroškim trgovcima Petru Đekoviću i Rasimu Bilalagiću celo pokućstvo, itd. ${ }^{48}$ Jedan dokument donosi podatak da su partizani do kraja januara 1942. u selu Toci napravili veliki magacin u kome su uskladištili oko „,150 tona žitarica“, konfiskovanih u selima na potezu Nova Varoš - Priboj. ${ }^{49}$

gubljene 264 osobe i to na sledeće načine: ,lobanje razbijane tupim predmetima; prebijane ruke i noge; grudni koš izrešetan kuršumima i izboden noževima; osiječeni nosevi; odrezano lice i izvađeni zubi“. Пљеваљски весник, 27. 4. 1942; Глас Црногораиа, 4. 4. 1942; VA, Ča, kut. 145, fasc. 1, dok. 34, 1; Вукота Реџић, 'Пасје гробље' у Колашину, (Београд: Евро, 1999), 58-62.

${ }^{44}$ AUSSME, Divisione „Pusteria“, bus. N-4/707, Allegato al bollettino informazioni nr. 194, 13. 2. $1942,2$.

${ }^{45}$ Станислав Краков, Генерал Милан Недић. Препуна чаша чемера, II (Београд: Нова искра, 2012), 93.

${ }^{46}$ AUSSME, Divisione „Pusteria“, busta N-5/821, Situazione militare, politica ed economica di Nova Varos, Allegato al foglio nr. 3941, 3. 7. 1942, 3.

${ }^{47}$ M. Djilas, Wartime, 120.

48 Златарске новости, 24. 1. 2002; Исто, 14. 6. 2002; Исто, 16. 8. 2002; Исто, 28. 8. 2002; Исто, 31. 7. 2003.

${ }^{49}$ AUSSME, Divisione „Pusteria“, bus. N-4/657, Bollettino informazioni nr. 182, 31. 1. 1942, 1. 
Jednako teška situacija po lokalno stanovništvo bila je u Pljevaljskom srezu, koji je tokom prve polovine 1942. godine postao jezgro partizanskog pokreta na teritoriji Starog Rasa. ${ }^{50}$ Poraz komunističkih snaga na Pljevljima podigao je lestvicu nasilja na još viši stepen. Jedan partizanski odred je boraveći 23. decembra u selima Odžaci i Potpeće tražio od muslimana da se pridruže pokretu, uz pretnju da će se spaliti kuće onima koji to odbiju. Iako su, na drugoj strani, u Krupicama partizani već bili sakupili 1.500 ovaca i 300 volova, nekoliko dana kasnije oduzeli su stoku i životne namirnice meštanima Kosanice i Brvenice. ${ }^{51}$

Zatim se tokom januara ideološki sukob u Pljevaljskom srezu zaoštrio do krajnjih granica. Pripadnici I pljevaljske i Drobnjačke partizanske čete uhvatili su 19. januara u selu Krnjači petoricu četničkih oficira. Među njima su bili: kapetan Petar Vojinović, kapetan Savo Damjanović, potporučnik Petar Jestrović, narednik Mirko Gogić i kapetan Boro Mitranović. Prva četvorica su ubijena na ,zverski način“, tako da su ,iznakaženi leševi“" tokom ukopa zaprepastili građane Pljevalja. ${ }^{52}$

Pljevaljska partizanska četa je posle ove egzekucije imala nekoliko sukoba sa legalizovanim četničkom odredom iz Pljevalja (komandant Pećančev vojvoda Ratko Đurović), čije je ljudstvo tražilo osvetu. ${ }^{53}$ Bilo je mrtvih i ranjenih na obe strane. Komunisti su pri tom zarobili četvoricu četnika. Svi su do 25. januara likvidirani. U istom partizanskom izveštaju se navodi da su pripadnici Pljevaljske čete likvidirali i „,8 ustaša iz Fočanskog sreza“. Uvidom u italijansku dokumentaciju može se bliže odrediti njihov identitet. Naime, 22. januara oko „20 muslimanskih izbeglica“ iz Foče prolazilo je kroz selo Meljak na putu ka Pljevljima. Partizani su ih napali, trojicu ubili, ostale zarobili, a imovinu im opljačkali. Verovatno su kasnije iz ove grupe likvidirali još pet osoba. ${ }^{54}$

Komunista Mišo Pavićević pisao je, takođe, da su partizani između 10. i 28. januara likvidirali Stjepana Jeftovića, ,pljačkaša četnika“ iz Čelebića i Spasoja Čepića, označenog kao ,italijanskog špijuna“ iz Hoćevine. U odsustvu su na smrt osuđeni muslimani: Šao Šljuka, Tahir Dizdar i Alija Bisić, koji su pobegli u Pljevlja. Šljuki i Dizdaru je konfiskovana celokupna imovina. Dokazni materijal nismo pronašli u arhivskoj građi. ${ }^{55}$ Egzekucije nad žrtvama ${ }^{56}$ su inače predvodili

${ }^{50}$ Ibid., bus. N-4/707, Notizie sulla zona Podpece - Odzak, 28. 3. 1942, 1.

${ }^{51}$ Ibid., bus. N-4/657, Bollettino informazioni nr. 143, 23. 12. 1942, 1; Ibid., nr. 155, 4. 1. 1942, 1; Ibid., nr. 156, 5. 1. 1942, 1.

52 VA, Ča, kut. 142, fasc. 4, dok. 54, 1; Богдан Гледовић, Едиб Хасанагић, Прибојски крај у Другом светском рату 1941-1945 (Прибој: СУБНОР, 2011), 57; Пљеваљски весник, 16. 2. 1942; Isto, 13. 7. 1942.

${ }^{53}$ Đurović se nalazio u otvorenoj kolaboraciji sa Italijanima, pa je štab jedinice smestio u Pljevlja. Funkciju njegovog načelnika vršio je kapetan Nikola Bojović. Đurović se potpisivao kao „Komandant Raških četničkih odreda“, dok ga je okupator imenovao zapovednikom „Sandžačkih četničkih odreda“. VA, Ča, kut. 144, fasc. 4, dok. 10, 1; Zavičajni muzej Pljevlja (ZMP), fond 4, NOB, Neprijateljska građa, inv. br. 8, 1-2; Пьеваљьски весник, 6. 7. 1942.

${ }^{54}$ AUSSME, Divisione,,Pusteria“, bus. N-4/657, Bollettino informazioni nr. 176, 25. 1. 1942, 1; Ibid., Bollettino informazioni nr. 173, 22. 1. 1942, 1; VA, NOVJ, kut. 1671, fasc. 1, dok. 15, 1.

${ }^{55}$ VA, NOVJ, kut. 1671, fasc. 1, dok. 15, 1-2.

${ }^{56}$ One su i ovde bile vrlo surove. Činovnik Mirko Gogić iz Gotovuške opštine usmrćen je udarcem sekirom (,tako da je mozak ispao“), a njegov leš je pronađen u jednoj „krečani 
politički komesari, koji su na taj način potvrđivali autoritet kod ljudstva. Među onima od kojih je stanovništvo pljevaljskog kraja najviše strepelo bili su: Žarko Vidović, Mišo Pavićević, Mirko Prijatović, Aleksa Jovičević i Ilija Zečević. ${ }^{57}$

U susednom Prijepoljskom srezu, u opštini Kamena Gora, komanda Crnogorsko-sandžačkog odreda je takođe likvidirala one za koje je smatrala da štete interesima KPJ. Po dojavi meštana sela Vrbova, seljanka Stana Koruća je 16. decembra streljana pod obrazloženjem da je služila kao kurir predsednika opštine u Prijepolju. Izvesni Jovan Dučić iz Karoševine je 8. januara optužen da je italijanski špijun. Iako na suđenju nije bilo čvrstih dokaza, on je izveden pred streljački stroj. Dva dana kasnije, sličnu sudbinu je podelio i Obrad Jeftović iz Zabrdnih Toca, kao bivši četnik. ${ }^{58}$

Početak februara 1942. doneo je novu neizvesnost. Na Kamenu Goru se prebacilo partizansko ljudstvo iz Nove Varoši, predvođeno Milovanom Đilasom. Na to su bili primorani usled poraza od snaga generala Nedića 5. i 6 . februara u blizini grada. Uzroci neuspeha pronađeni su, gledano kroz ideološku prizmu, u „,neprijatelju iznutra“. Đilas je, iako nije služio vojsku, pisao da se u njegovim trupama, navodno, nalazio „strašan ološ“. Pomenuti Sveto Milutinović se prisećao da je na Kamenoj Gori ,izvršena reorganizacija, a onda je došlo do tog čišćenja“. To potvrđuju i Velisav Stanković, partizan iz Užica, kao i poznati hroničar ratnih događaja - Vladimir Dedijer.

Novo čišćenje ljudstva odnelo je još nekoliko života. Tako je partizan Pivljaković, star 17 godina, iz II zlatarskog bataljona, pogubljen zato što je ukrao donji veš jer svoj nije imao, a patio je od promrzlina posle prelaska Lima. Rus Novožilov je ubijen jer je Đilas zaključio da je on „ološ“ $i$,dvolični element", iako je za hrabrost bio pohvaljen u Biltenu VŠJ. Osamnaestogodišnji Milutin Bučevac iz Bistrice likvidiran je pod optužbom da je negde ukrao britvu. Ista sudbina je zadesila i partizane: Vladu Miladinovića, Radoša Nikolića (član KPJ), Čedu Čenića, Vanjku Hadžića, Žiku Markovića i još dvojicu boraca od kojih je poznato da se jedan zvao Marko. Zajedno sa njima pogubljen je četnički komandant sela Lučice, zarobljen prilikom partizanskog prelaska Lima.

$\mathrm{Na}$ drugoj strani, deo boraca je po Đilasovom naređenju jednostavno izbačen iz stroja, razoružan i poslat u Crnu Goru da se snalazi kako zna i ume. Pripadnici ove grupe su opomenuti da više ,ne smeju imati nikakve veze sa partizanima“" (oko 100 muškaraca i žena). Među njima je dosta ljudi nastradalo od promrzlina i(li) četnika, pre nego što je uspelo da se vrati u partizanske jedinice. ${ }^{59}$

potpuno go“. Obradu Vučiniću iz Premćanske opštine partizani su ,izvadili oči i slomili ruke“, dok je Savo Kobur iz Otilovićke opštine ,izmrcvaren pa streljan“. Пакао или комунизам у Црној Гори (Цетиње: Глас Црногораца, 1943), св. 1, 21; Isto, sv. 8, 26.

${ }^{57}$ AUSSME, Divisione,,Pusteria“, bus. N-4/706, Bollettino informazioni nr. 260, 18. 4. 1942, 2.

58 AUSSME, Divisione „Pusteria“, N-4/657, Bollettino informazioni nr. 156, 5. 1. 1942, 1; Пакао или комунизам у Црној Гори, св. 1, 15.

${ }^{59}$ VA, NOVJ, kut. 3, fasc. 3, dok. 1, 3; IAU, MG, d. 1280, 11-12; Isto, d. 1471, 25-26; Isto, d. 90, 24-25; Златарске новости, 26. 10. 2001; V. Dedijer, Veliki buntovnik, 174, 179, 263-264, 266-267; M. Djilas, Wartime, 136. 
U Pljevaljskom srezu je, u međuvremenu, 13. februara oko 50 partizana upalo u selo Vlahovići i pokušalo da pokupi hranu i razoruža meštane. Kada su ovi pružili otpor, partizani su opkolili njihove kuće i zapucali. Iz haosa koji je usledio, većina meštana se izbavila bekstvom četnicima u selo Ilino Brdo. ${ }^{60}$ Istovremeno je Mileševski bataljon napao četnike u selu Zaostro, južno od Pljevalja. Posle kraće borbe partizani su opljačkali stoku, žito, pasulj i druge životne namirnice od četničkih porodica. O paljenju imovine i pljačkanju pročetničkih familija tokom februara govori i savremenik tih događaja komunista Mirko Ćuković. On navodi da su nekada ove akcije išle i mimo naređenja lokalnih narodnooslobodilačkih odbora $(\mathrm{NOO}){ }^{61}$

Postupci komunista izazivali su sve veće nezadovoljstvo među stanovništvom obe veroispovesti. Samim tim ono se prenosilo i u njihove jedinice, iako je Broz smatrao da je rad KPJ na teritoriji Starog Rasa zadovoljavajući. ${ }^{62}$ Ponašanje partizana izazivalo je, takođe, sve češće ispade italijanskog okupatora iz Pljevalja sa legalizovanim četnicima, koje su pratile masovne represalije nad seoskim stanovništvom, pogotovo nad partizanskim porodicama. Kao reakciju na to, VŠJ je krajem februara tražio od kadrova angažovanih pri GŠS-u, što se pre svega odnosilo na Pljevaljski srez, da zanemare sukobe sa italijanskom vojskom i glavna dejstva usmere ,protiv četnika“. Dokument koji je potpisao kapetan Arso Jovanović završava se instrukcijom koja glasi: „Razoružajte i likvidirajte sve one na koje se može posumnjati da će sjutra biti naši neprijatelji“ ${ }^{63} \mathrm{Sa}$ tim naređenjima se ušlo u mesec mart 1942. godine.

GŠS je već 4. marta naredio širu akciju protiv četnika i napad na njihove položaje u Židovićima, Bušnjama i Kotlinama, gde se nalazio kapetan Nikola Bojović. Cilj akcije bio je da se četnici potisnu i konfiskuje imovina onima koji stupili u njihove redove. Bojović je uspeo da odstupi sa ljudstvom, ali je njihova imovina u Židovićima, Bušnjama, Brvenici, Gotovuši, Kotlinama i Krćama opljačkana. U izveštaju VŠJ se navodi da je ,zaplena četničke imovine - naročito volova zbog oranja - jako pogađala njihove porodice“. Pripadnici II zlatarskog bataljona su istovremeno napravili ispad iz Pljevaljskog sreza i napali četnike u selu Zaborku, Čajnički srez. Njihova jedinica je razbijena, a četnički rukovodioci ,pohvatani i streljani“ ${ }^{6}{ }^{4}$

${ }^{60}$ AUSSME, Divisione,,Pusteria“, bus. N-4/657, Bollettino informazioni nr. 194, 12. 2. 1942, 1.

${ }^{61}$ Б. Гледовић, Е. Хасанагић, н.. д., 102; Мирко Ћуковић, „Народноослободилачка власт у бившем Санџаку“, у: Народноослободилачка борба и сочијалистичка револуција у Саниаку, уредник Петар Влаховић (Пријепоље: СИЗ основног образовања, 1981), 143, 145, 151.

${ }^{62} \mathrm{AJ}$, fond 507, CK SKJ, MG, d. 2506, 25.

${ }^{63}$ VA, NOVJ, kut. 2A, fasc. 1, dok. 34, 1. Koliko se ozbiljno GŠS posvetio sprovođenju ovog naređenja, govori dokument u kojem stoji da su partizani tokom marta i aprila ,pružali slab otpor napadima italijanskih trupa“, dok su na drugoj strani „tražili posebno“ četničke formacije i njihove porodice da bi ih „uništili“. AUSSME, Divisione „Pusteria“, bus. N-5/821, Allegato nr. 1 al bolletino informazione nr. 305, 2 .

${ }^{64}$ VA, NOVJ, kut. 1671, fasc. 10/I, dok. 1, 1; Bogdan Gledović, Prilog u krvi: Pljevlja 19411945 (Pljevlja: Pljevaljske novine, 1969), 86-87; Б. Гледовић, Е. Хасанагић, н. д., 102. 
Odgovor okupatora je usledio ubrzo. Njihova vojska je spalila Boljaniće i umalo uništila GŠS. Pridržavajući se radikalno-klasnog principa, VŠJ je naredio da se zauzme još rigorozniji stav prema neprijateljima KPJ. U naređenju od 7. marta doslovno stoji: „Likvidirajte hitno četničke snage u Pljevaljskom srezu. Ako neko izbegne od četnika, treba mu svu imovinu konfiskovati, paleći i kuće da se nemaju gde vratiti“. ${ }^{65}$ Sedam dana kasnije Josip Broz odlazi i korak dalje. Njegova zapovest od 14. marta kaže da ako bi četnici nastavili da beže u Pljevlja, pored konfiskacije imovine i paljenja kuća, trebalo bi upotrebiti i ,jače represalije“. 66

Šta se, između ostalog, krilo iza ovih reči, slikovito govori partizanski pristup rekviziciji životnih namirnica. Prilikom oduzimanja četničke imovine nosilo se sve što se moglo iskoristiti na bilo koji način. Što su partizanske jedinice bile u težem stanju, konfiskacije su bile intenzivnije. Dešavalo se da se rekvizicija otme kontroli, pa su se na udaru znala naći i muslimanska, ${ }^{67}$ ali i partizanska domaćinstva. ${ }^{68}$ Velisav Stanković, intendant Užičkog bataljona, sećao se posle rata da mu je izuzetno teško padao ceo proces prikupljanja hrane od seljaka, ${ }^{69}$ pogotovo što je na prostoru Crne Gore i Starog Rasa u to vreme već uveliko vladala glad.

Iako se opšta bezbednosna situacija u Pljevaljskom i delovima Prijepoljskog sreza (leva obala Lima) pod kontrolom partizana konstantno pogoršavala, rukovodstvo KPJ nije odstupalo od zacrtanog kursa. Načelnik VŠJ Arso Jovanović je polovinom marta podsetio lokalne komuniste da kod Pljevalja nastave sprovođenje „strogo represivnih mera“ dok se sa ideološkim neprijateljem definitivno ne „raščisti“،. Dodao je da se svi koji odbiju ova naređenja streljaju kao „kolebljivci“ ${ }^{70}$ Oko 150 partizana je, stoga, 26. marta upalo u selo Barice u Prijepoljskom srezu i zapalilo i opljačkalo sve četničke kuće. Dva dana kasnije usledila je partizanska ofanziva u selima Jugovo, Gotovuša, Brvenica,

${ }^{65}$ VA, NOVJ, kut. 2A, fasc. 2, dok. 16, 1. Treba reći da je pljačka imovine pored represivne imala i praktičnu svrhu. U vreme raširene gladi ona je predstavljala najsigurniji vid redovne ishrane. Intenzitet ovog vida represalija se, stoga, javlja kao jedan od faktora koji su uticali na brojnost partizanskih trupa. NOO za Pljevaljski srez je, na primer, zabeležio da porodice šalju svoje članove u komunističke jedinice, ne bi li tamo, pre svega, dobili „odelo i hranu“. VA, mikrofilmovi, NVP, NOB, r. 1, 25, 104, 192, 195, 209, 296.

${ }^{66}$ VA, NOVJ, kut. 2A, fasc. 2, dok. 24, 1-2.

${ }^{67}$ Iz Bukovičke opštine, pretežno naseljene muslimanima, partizani su konfiskovali imovinu u visini od oko 87.000 italijanskih lira. Пакао или комунизам у Црној Гори, св. 2, 20; Исто, св. 5, 23.

${ }^{68}$ VA, mikrofilmovi, NVP, NOB, r. 1, 58, 203, 291.

${ }^{69}$ Stanković slikovito opisuje odnos naroda prema partizanima: „Kad intendanti dođu u selo, onda nastane jedno veće plakanje ko će koliko dati od seljaka, ali kad mi polazimo iz sela svi od radosti plaču“. IAU, MG, d. 90, 28-29.

${ }^{70} \mathrm{Da}$ bi se u ovakvoj atmosferi očuvala borbena i idejna kohezija odreda, među ljudstvo su ubacivani špijuni koji su lično komesarima prenosili bilo kakvu aluziju protiv komunista u stroju. Tako je napetost u jedinicama dostigla vrhunac pa su se borci, pored pritiska spolja, našli i pod psihološkim pritiskom iznutra. On se, zatim, prelivao u nasilje prema neprijatelju. AUSSME, Divisione „Pusteria“, bus. N-5/821, Allegato nr. 1 al bolletino informazione nr. 305, 2; VA, NOVJ, kut. 21, fasc. 2, dok. 30, 1. 
Stup i Glisnica, sve u Pljevaljskom srezu. Kada su četničke formacije razbijene, pristupilo se paljenju njihovih kuća i konfiskaciji imovine. ${ }^{71}$ Posle ovih akcija veliki broj četničkih familija bio je proteran iz svojih sela ka Pljevljima, što je VŠJ pozdravio. ${ }^{72}$

Za njima su, međutim, u zbeg krenuli i svi oni koji su smatrali da bi ih partizani na bilo koji način mogli prepoznati kao protivnike. Zapretila je opasnost da pojedina naselja opuste. Primer za to je veliko selo Kosanica. Svi njeni meštani su se u jednom trenutku jednostavno razbežali. Partizani su ih 19. marta pozvali da se vrate u roku od dva dana i predaju oružje. Bezbednost je garantovana svima, sem onima koji su ranije učestvovali u paljenju kuća komunističkih porodica. Zaprećeno im je uništenjem kuća i konfiskacijom imovine ako se ne povinuju želji partizanske komande. ${ }^{73}$ Egzodus Kosaničana će, ipak, potrajati.

Josip Broz je početkom aprila 1942. odlučio da suspenduje odluke o radikalizaciji klasne borbe. Međutim, proces koji je do tada prožeo sve slojeve društva, pogotovo na selu, nije mogao tek tako biti obustavljen. Suprotno naređenjima rukovodstva KPJ, teror se u Pljevaljskom i Prijepoljskom srezu spontano nastavio i, čak, pojačao. Početkom aprila partizani su upali u Jugovo, popalili kuće i opljačkali domaćinstva četničkih familija, dok su njihove rođake mučili. Potom je 6. aprila jedna žena iz Kovača poslata u Pljevlja da pozove izbeglice iz ovog mesta da se odmah vrate. Protiv onih koji to ne bi učinili, trebalo je sprovesti ,teške represalije“. O tome šta se verovatno desilo, govori nam izveštaj GŠS upućen VŠJ da su tih dana likvidirane „manje grupe četnika i špijuna“, kao i da je vršena zaplena dobara tokom koje je ,,popaljeno nekoliko kuća““ 74

Partizani su ponovo napadali i verske objekte. Tako su borci Zlatarskog bataljona 9. aprila zaplenili dva konja natovarena drvima, vlasništvo manastira Sv. Trojice. Konjovocu su dali priznanicu i zapretili mu da će zapaliti manastir ako se bude žalio italijanskim vlastima. Pošto je slučaj, ipak, prijavljen, komunisti su pokušali da podmetnu požar u hramu. Pre nego što su monasi ugasili vatru, stradao je deo manastirskog konaka. ${ }^{75}$

U susednom Prijepoljskom srezu partizani su 20. aprila upali u selo Skokuće i počeli da plene stočnu hranu ,pucajući na seljake koji su se protivili“. Nismo utvrdili da li je neko od meštana stradao. Tri dana kasnije gerilci sa Kamene Gore su u naselju Velika Župa ,zapalili neke kuće i opljačkali sve što je bilo u njima“. Pri tom su stradala kako hrišćanska tako i muslimanska domaćinstva. Kakva je bila uspešnost ovih akcija, možemo videti iz dopisa komande Mileševskog bataljona GŠS, poslatog 21. aprila. U njemu stoji da je snabdevanje jedinice u potpunosti prebačeno, ,na teret neprijatelja naše borbe“، ${ }^{76}$

\footnotetext{
${ }^{71}$ Ibid., bus. N-4/707, Bollettino informazioni nr. 239, 28. 3. 1942, 1; Ibid., nr. 240, 29. 3. 1942, 1.

72 VA, NOVJ, kut. 2A, fasc. 2, dok. 32, 1.

${ }^{73}$ AUSSME, Divisione „Pusteria“, bus. N-4/707, Bollettino informazioni nr. 234, 23. 3. 1942, 1.

74 Ibid., bus. N-4/706, Bollettino informazioni nr. 245, 3. 4. 1942, 1; Ibid., nr. 248, 6. 4. 1942, 1; VA, NOVJ, kut. 1671, fasc. 10/I, dok. 4, 1.

${ }^{75}$ Ibid., nr. 252, 10. 4. 1942, 2.

${ }^{76}$ VA, NOVJ, 1671-14/1, 1; ASŽ, Ž-30, ZF, kut. 206, 43.
} 
Istovremeno, partizani su se vratili u Kosanicu da bi proverili uticaj svojih pretnji na lokalni živalj. Pošto su opljačkali i ognju prepustili veći broj kuća, možemo pretpostaviti da nisu bili zadovoljni. Bilo kako bilo, „oko 500 osoba, većinom žena i dece“ su ,izbačeni iz svojih kuća bez prilike da ponesu sa sobom ni odeću, niti osnovne potrebštine“. Izbeglice su se smestile u susedno Ilino Brdo, izazivajući tamo probleme oko ishrane i smeštaja lokalnom življu. Dva dana potom istom tretmanu bili su izloženi i stanovnici sela Mataruga. Tamo je opljačkano više desetina kuća, a oko 50 pročetničkih porodica rasterano na više strana. Komunisti su paralelno sa time pokupili stanovništvo sela Jabuke i poveli ga u borbu sa četnicima. Deo seljaka se pobunio jer nije želeo da napusti svoja ognjišta. Pošto je jedno lice zbog toga streljano, mobilizacija je sprovedena bez teškoća. $^{77}$

Usled italijansko-četničke ofanzive širom Crne Gore i Starog Rasa početkom maja 1942. godine, partizanske pozicije u Pljevaljskom i Prijepoljskom srezu su se pogoršale. Stoga se revolucionarni teror proredio. Ljudstvo je, i pored toga, počelo da se osipa i gubi ratni elan. Dana 12. maja, na primer, iz II pljevaljskog bataljona dezertiralo je čak 70 boraca. Partizanska komanda reagovala je likvidacijama. Posle sprovedene istrage krivica je pala na osam lica, među kojima su bila dvojica žandarma, jedan finans i nekoliko „,bivših bosanskih četnika“. ${ }^{78}$ Komanda „Pusterije“ raspolagala je podacima da je zbog ovog slučaja dezertiranja u Pljevaljski srez lično došao Moše Pijade. On je, prema istom izvoru, i naredio streljanja. ${ }^{79}$ Čišćenje borbenih redova olovom nije dalo očekivane rezultate. To nam govori podatak da je kroz nekoliko dana položaj bez dozvole napustilo još 14 partizana iz I pljevaljskog bataljona. Ceh su platila trojica njihovih saboraca. Jedan je streljan zbog širenja panike, a druga dvojica jer su ukrali nešto žita. ${ }^{80}$

Komunistima je postajalo sve teže da snabdevaju ljudstvo hranom, pa se nastavilo sa otimanjem hrane od stanovništva. Intendantura GŠS-a je pisala 16. maja Pljevaljskom NOO da ako joj se ne dostave tražene namirnice, ona će to smatrati za sabotažu i preduzeti neophodne mere da se iste prikupe bez obzira na žrtve. Nedostatak je nadoknađen konfiskovanjem imovine muslimana iz selâ Maoča, Pračice i Graca, koji su se zbog čestih borbi partizana i četnika sklonili u Pljevlja. ${ }^{81}$ Bila je ovo jedna od poslednjih partizanskih akcija u Pljevaljskom srezu, budući da su do početka juna potisnuti iz Starog Rasa, zajedničkim naporom okupatorskih snaga i četnika. Na ove prostore partizani će se vratiti tek deset meseci kasnije, ali sa znatno većim borbenim potencijalom. U međuvre-

\footnotetext{
77 AUSSME, Divisione „Pusteria“, bus. N-4/706, Bollettino informazioni nr. 263, 21. 4. 1942, 1; Ibid., nr. 266, 24. 4. 1942, 2.

78 Tada su likvidirani: Danilo, Miloica i Miladin Borović, Tripko Nenezić, Stevan Karadžić, Maksim Popara, Mirko Gazdić i Dušan Kotlaja. VA, NOVJ, kut. 1671, fasc. 10/I, dok. 13, 1; VA, mikrofilmovi, CK SK Crne Gore NOB, rol. 1, 671; VA, NOVJ, kut. 1671, fasc. 10/I, dok. 1,1 ; Isto, dok. $2,1$.

79 AUSSME, Divisione „Pusteria“, bus. N-4/706, Bollettino informazioni nr. 297, 25. 5. 1942, 1.

${ }^{80}$ Ibid., bus. N-5/821, Allegato nr. 1 al bolletino informazione nr. 305, 2-3.

${ }^{81}$ VA, mikrofilmovi, NVP, NOB, r. 1, 16, 208.
} 
menu, na teritoriji sa koje su se povukli ostale su ,trojke“ koje su krstarile prostorom i napadale, uglavnom, pojedince odane četnicima. ${ }^{82}$

Od novembra 1941. do maja 1942. bilans komunističkih ,levih skretanja“" u Pljevaljskom srezu predstavlja: na desetine ubijenih osoba, stotine raseljenih lica i spaljenih kuća, kao i velika količina opljačkane hrane i stoke. Prema podacima divizije „Pusterija“, na teritoriji Pljevaljskog sreza je od strane komunista likvidirano 58 lica obe veroispovesti. ${ }^{83}$ Ukoliko tom broju dodamo 11 partizana streljanih u maju, dolazimo do brojke od 69 ubijenih osoba u pljevaljskom kraju tokom pomenutog vremenskog perioda. ${ }^{84}$

Bilans revolucionarnog terora (prema do sada prikupljenim podacima)

\begin{tabular}{|l|r|r|r|}
\hline & Likvidirana lica & Paljevine sela & \multicolumn{2}{|c|}{ Pljačke sela } \\
\hline Novovaroški srez & 109 & - & 8 \\
\hline Prijepoljski srez & 14 & 3 & 5 \\
\hline Pljevaljski srez & 69 & 7 & 19 \\
\hline Ukupno & $\mathbf{1 9 2}$ & $\mathbf{1 0}$ & $\mathbf{3 2}$ \\
\hline
\end{tabular}

Može se zaključiti da se komunističko nasilje u novovaroškom, prijepoljskom i pljevaljskom kraju odvijalo tokom tri vremenska perioda, u tri pravca i na tri načina. Radikalizacija klasne borbe tekla je u fazama: oktobardecembar 1941, decembar 1941-februar 1942. i februar-maj 1942. godine. Za to vreme revolucionarni teror je tekao u tri rukavca. Prvi je bio usmeren na ,unutrašnjeg neprijatelja“, tj. navodno nesigurne i neprijateljski raspoložene borce unutar partizanskih snaga i, čak, unutar KPJ - ,čišćenje“ Ariljske čete, ubistvo partizana Pivljakovića, Novožilova, Hadžića, Čenića, Nenezića, Kotlaje i drugih, zatim članova KPJ Milana Cvetića i Radoša Nikolića itd.

Oštrica drugog pravca pogodila je sve one koji su smatrani ,ideološkim neprijateljima“. Stoga stradaju ljudi drugačijeg društvenog statusa od onog na koji su se oslanjali i iz kog su, uglavnom, poticali komunisti. Pomenimo igumane Džarića i Trkulju, bogoslova Vrbickog, četničkog vojvodu Ćurčića, inženjera Ranitovića, pravnika Purića, profesora Miletića i učitelja Purića. Svi oni su likvidirani pre dolaska partizanske vojske iz Užica, što jasno govori da se termin početka revolucionarnog terora mora vratiti barem mesec dana unazad od do sada opšteprihvaćenog. Nastavak gornjeg niza izgleda ovako: oficiri Vojino-

82 Partizani su već 19. juna na Zlataru uhvatili i likvidirali kapetana Milana Durutovića i bivšeg narodnog poslanika i profesora filozofije Milutina Jelića. VA, Ča, kut. 127, fasc. 10, dok. 19, 1; IAU, MG, d. 1568, 5.

${ }^{83}$ AUSSME, Divisione,„Pusteria“, bus. N-5/821, Ufficio del capo di S. M., Sezione informazioni, Statistica relativa al Distreto di Pljevlja, 16. 7. 1942, 1-3. Pomenućemo i žrtve komunista u Bijepoljskom i Pribojskom srezu tokom istog perioda. U pitanju su 44 lica u opštinama Šahovići, Ravna Rijeka, odnosno Zabrđe i Priboj. VA, Ča, kut. 132, fasc. 1, dok. 19, 2; Isto, kut. 298, fasc. 1, dok. 4, 21; Пакао или комунизам у Црној Гори, св. 3, 14; Исто, св. 5, 17; Исто, св. 7, 18-19; Исто, св. 8, 25.

${ }^{84}$ Imena ubijenih popisao je i objavio kolaboracioni list Glas Crnogoraca tokom 1943. godine. U spiskovima se nalazi nešto veći broj ubijenih - 72 lica. Пакао или комунизам у Црној Гори, св. 1, 21-22; Исто, св. 3, 12, 14; Исто, св. 5, 9, 17-18; Исто, св. 7, 17-18; Исто, св. 8, 25. 
vić, Damjanović, Jestrović i Durutović, profesor Jelić, učitelj Vitorović, „solunci“ Cmiljanić i Popović. Pritisak je osetilo i civilno stanovništvo koje se nije slagalo ili se otvoreno protivilo politici KPJ (streljanja talaca iz Rutoša, zarobljenih seljaka u Kokinom Brodu, meštana Aljinovića, Vlahovića, Kosatice itd.).

Grubo gledano, revolucionarno nasilje je imalo tri oblika. Prvi se ogledao u čestim, nekada i masovnim, likvidacijama, uglavnom bez jasno utvrđene i(li) neodređene krivice. Drugi i treći su pogađali seoski živalj i to kroz zaplenu hrane i imovine, paljenje kuća i proterivanja njihovih stanovnika. Kako drugačije objasniti opljačkana domaćinstva u selima: Rutoše, Kosanica, Bukovica, Barice, Velika Župa, Jugovo, Stup, Glisnica, Skokuće itd.; popaljene kuće u: Zaostru, Kosanici, Židovićima, Bušnju, Krćama, Kotlinama, Gotovuši i Matarugama, te proterivanje ,500 žena i dece“ iz Kosanice i još nekoliko stotina ljudi iz Mataruga, da se bez ikakvih sredstava snalaze u planinama po velikoj zimi.

U članku smo na više mesta videli i da su partizanske egzekucije u određenom stepenu poprimile surove oblike. Žrtve su potapane u ključalu vodu, paljeni su im brade i brkovi, izbijani zubi, odsecani udovi, uši i nosevi, vađene oči i drugi organi. Prednost nad vatrenim, često je davana hladnom oružju - kamama, sekirama, maljevima. Posebno ponižavajuće bilo je skidanje žrtava do gole kože po hladnom vremenu, njihova likvidacija u "gluvo“ doba noći, nepokopavanje leševa ili njihovo bacanje u krečane i dr. Bizarno, takođe, deluje podatak da je partizanska komanda u Novoj Varoši imala posebnu grupu dželata, zaduženu samo za hvatanje i ubijanje lica određenih za likvidaciju i to isključivo po mrklom mraku. 


\section{REFERENCE}

- Ćuković, Mirko. Putovanje u slobodu: ratne beleške. Nova Varoš: SIZ kulture Opštine, 1979.

- Ćuković, Mirko. „Narodnooslobodilačka vlast u bivšem Sandžaku“. U: Narodnooslobodilačka borba i socijalistička revolucija u Sandžaku. Urednik Petar Vlahović, 143-151. Prijepolje: SIZ osnovnog obrazovanja, 1981.

- Dedijer, Vladimir. Dnevnik: 1941-1944. knj. I. Beograd-Sarajevo: ProsvetaSvjetlost, 1970, 1970.

- Dedijer, Vladimir. Veliki buntovnik Milovan Đilas. Beograd: Prosveta, 1991.

- Đilas, Milovan. Druženje s Titom. Beograd: Goran, 1990.

- Djilas, Milovan. Wartime. New York: Harcourt Brace Jovanovich, 1977.

- Gledović, Bogdan. Prilog u krvi: Pljevlja 1941-1945. Pljevlja: Pljevaljske novine, 1969.

- Gledović Bogdan, i Edib Hasanagić. Pribojski kraj u Drugom svetskom ratu 1941-1945. Priboj: SUBNOR, 2011.

- Glišić, Venceslav. Susreti i razgovori. Prilozi za biografiju Petra Stambolića. Beograd: Službeni glasnik, 2010.

- Hasanagić, Hilmija. U surovoj školi. Beograd: Prosveta, 1962.

- Krakov, Stanislav. General Milan Nedić. Prepuna čaša čemera. Knj. II, Beograd: Nova iskra, 2012.

- Nikolić, Kosta. Istorija Ravnogorskog pokreta: 1941-1945, knj. I. Beograd: Zavod za udžbenike, 2014.

- Nikolić, Kosta. Tito govori što narod misli. Beograd: Institut za savremenu istoriju, Službeni list SCG, 2006.

- Petranović, Branko. „O levim skretanjima KPJ krajem 1941. i u prvoj polovini 1942. godine“. Zbornik za istoriju Matice srpske, br. 4, (1971), 39-81.

- Petranović, Branko. Srbija u Drugom svetskom ratu 1939-1945. Beograd: Vojno-izdavački centar, 1992.

- Ravić, Stanko. Među orlovima Zlatara. Prijepolje: Polimlje, 1972.

- Redžić, Vukota. 'Pasje groblje' u Kolašinu. Beograd: Evro, 1999.

- Šaponjić, J. Vladimir. Krv uvačkih pećina i druge noćne more. Beograd: Draslav partner, 2013.

- Živković, Milutin. Nezavisna Država Hrvatska u Srbiji 1941. Ustaški režim u Priboju, Prijepolju, Novoj Varoši i Sjenici (april - septembar 1941). Beograd: Društvo istoričara Srbije, 2018. 
MILUTIN ŽIVKOVIĆ, PhD, Research Associate

Institute for Serbian Culture

Priština - Leposavić, Republic of Serbia

mzivkovickv@gmail.com

\title{
REVOLUTIONARY TERROR IN THE COUNTIES \\ OF NOVA VAROŠ, PRIJEPOLJE AND PLJEVLJA \\ OCTOBER 1941-MAY 1942
}

\begin{abstract}
Summary
Revolutionary terror in the regions of Nova Varoš, Prijepolje and Pljevlja was developing throughout three time periods, in three directions and in three ways. Radicalization of class conflict was unfolding in the following phases: October-December 1941, December 1941-February 1942 and February-May 1942. In the course of the said periods, class conflict was directed towards three target groups. The first was "internal enemy" i. e. allegedly unreliable and hostile fighters within partisan forces and even within CPY. The second referred to all those considered as "ideological enemies" while the third one referred to the population opposing the orders of the CPY. The most frequent forms of punishment were executions (sometimes even mass) mostly without clearly determined verdict, seizure of the property, expulsion from homes and (or) burning the homes down. In that way partisans killed (sometimes in very brutal ways) more than 190 people in regions of Nova Varoš, Prijepolje and Pljevlja. Most affected by communist repression were citizens of Nova Varoš Pljevlja and its surrounding. Consequently, both the partisans movement and the CPY as its vanguard lost the support of the local population, which fought back and started turning to the Chetniks.
\end{abstract}

KEYWORDS: terror, Josip Broz Tito, Milovan Đilas, Nova Varoš, Pljevlja, Prijepolje, Partisans, Chetniks 